ISSN 1112-9867

http://www.jfas.info

\title{
RELATION BETWEEN PROTOCOL TEST DIGITAL SIT AND REACH WITH BACK SAVER SITS AND REACHESBETWEEN 10 YEARS OLD IN PRIMARY SCHOOL
}

\author{
N. Salimin", M. N. F. M. Zainuri, M. I. Shahril, R. Jaafarand, M. Sankaravel \\ Faculty Sports Science and Coaching, UniversitiPendidikan Sultan Idris, TanjungMalim, \\ Perak, Malaysia
}

Published online: 17 October 2017

\begin{abstract}
The purpose of this study is to look into the relationship between Protocol Test Digital Sit and Reach (DSR) with Back Saver Sits and Reach (BSR) among students aged 10 in primary school. This study is designed based upon the correlation method between the test score and the descriptive statistical analysis. Total $(\mathrm{N}=60)$ students aged 10 years from SKJalan Hang Tuah 2, Kuala Lumpur was chosen as samples. The results on the validity showedstrong correlation between DSR and BSR $(r=0.93, p=0.001, p<0.001)$, meanwhile the reliability of DSR ( $r=0.97, N=60, p<0.001)$. Overall, DSRcan be used to assess the flexibility of the biceps femoris and back of the body. However, the DSR instruments should be tested with large populations to determine the validity and reliability of a more consistent.
\end{abstract}

Keywords: flexibility;physical education;fitness test;sit and reach.

Author Correspondence, e-mail: norkhalid@fsskj.upsi.edu.my

doi: http://dx.doi.org/10.4314/jfas.v9i5s.5 


\section{INTRODUCTION}

Public awareness of health and fitness has to moulda healthy lifestyle among the public. Studies have shown that the problems of diseases such as hypertension, heart disease and diabetes are dueto inactive or sedentary lifestyle [1-7]. Children in primary school have also been identified of having problems of overweight or obesity. The have found that a total number of 222 students from primary and secondary schools around Kuala Lumpur are obese [8]. It is also supported by a study in Malaysia, which shows that the status of fitness components,including the flexibility component of male students in preschool, primary and secondary school is low [9-10].

Flexibility is defined as an individual's ability to move parts from the body in an absolute range without feeling the pain about the joints and muscles [11]. Flexibility referred to the range of movement related to joints [12]. The ranges of movement that exists among individuals are different from each other. A standard assessment known as National Physical Fitness Standard Assessment Program for Malaysian Students (NPFS) was designed to be implemented at the school starting from 2008. National Physical Fitness Standard Assessment Program for Malaysian Students is a set of health-based standard physical fitness tests to measure physical fitness levels of primary and secondary students.

The relevant article entitled NPFS in the implementation of Physical Education in primary and secondary schools in Malaysia explained the issue of NPFStests implementation is due to the irregular administrative exam procedures at school, incomprehension and confusion of teachers about the test procedures and disagreement of ideas in performing the test [13]. The study is to observe the use of Protocol Test Digital Sit and Reach (DSR)in resolving issues and problems aroseduring the implementation of NPFS test. Furthermore, the findings of DSR willbe compared with different type of flexibility test to identify the correlation between the scores on both tests which involve flexibility components.

There is a low significant difference between the level of primary school students with secondary school students [14]. While the other studies that have been conducted shows an increase in the flexibility component among secondary school students [10]. Through the establishment of DSR instrument, it combines learning theories that are physical fitness 
[15] and motor behavior theory [16]. Researchers also use the ADDIE model as a reference in developing these testing tools [17]. Health-based fitness is based on five components that are cardiovascular endurance, muscular endurance, muscular strength, flexibility and body composition. While the use of motor behavior theory involves special movement during transition stage. At this stage, the respondents haveto own the development of motor behavior capacity and have sufficient knowledge to apply the various movements in everyday life usage. For flexibility behavior, it should involve the large muscle of thigh biceps brachii and latissusdorsil in performing a movement.

In designing DSR, the process that should be considered in this innovated tool is to meet the standard specifications of learning process. ADDIE model is applied so that the testing process is implemented effectively and systematically. It involves Analyze, Design, Develop, Implement and Evaluate.

The objectives of the study are as follows:

i. To identify the relationship between the scores of DSR and Backsaver Sit and Reach (BSR) among students aged 10.

ii. To identify the relationship between the scores of pre-test and post-test in the DSR of primary school students aged 10 .

iii. To identify the functionality of muscle in DSR for primary school students aged 10 .

\section{METHODOLOGY}

This study was conducted to examine the significant relationship between DSR with BSR. Then, electromyography tests were done on DSR tool to see the functionality of muscles involved. The results from the analysis is showing the correlation and the students' achievement scores in DSR with BSR and the functionality of muscles in DSR test.The sample consists of 60 students aged 10 who are randomly selected among the students of SKJalan Hang Tuah 2, Kuala Lumpur. There are 25 boys and 35 girls. The rationale behind the selection of the samples 10 years old because researchers assume logically that the students aged 10 years and above will have to follow NPFS test every year to examine their physical fitness level. 
The study used three main instruments DSR, BSR and electromyography test.

\subsection{Protocol Test Digital Sit and Reach}
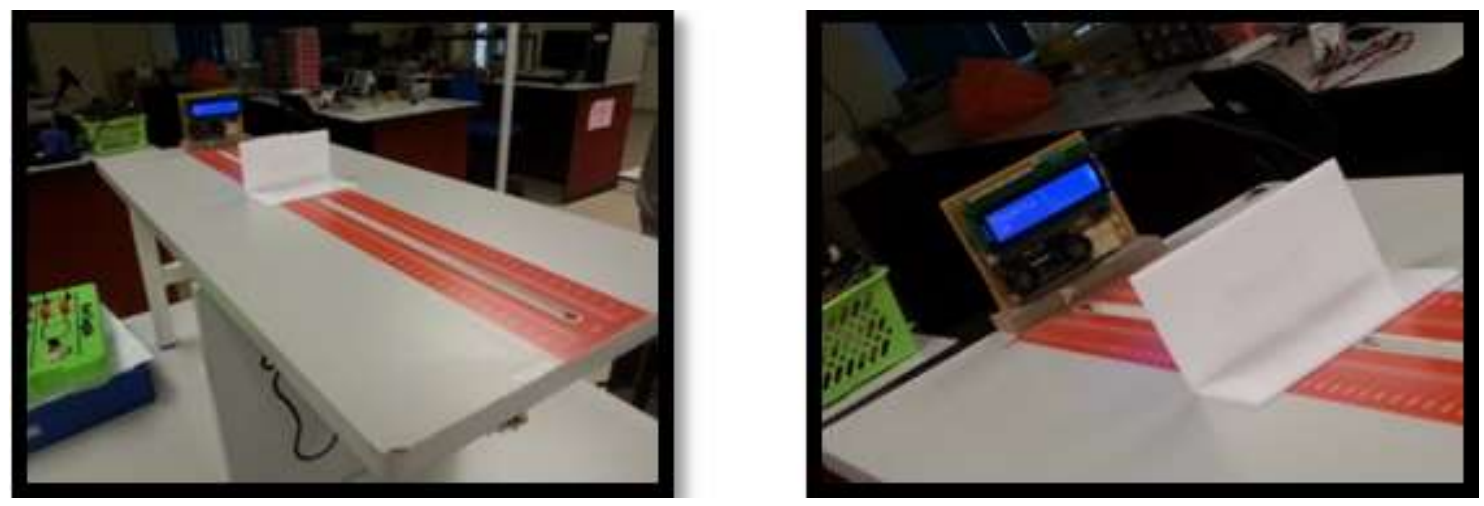

Fig.1. Digital sit and reach (DSR) instrument

Purpose: To measure flexibility of body back, thighs and hip (lower back andposterior thighs).

Level: 10 years old.

Gender: Male and female.

Tools: Gauge range equipment, ultrasonic sensor URM37 DFROBOT V3.2 (program $1 \mathrm{~cm}$ ), DC power adapter 7 volt and gauge.

Test Procedures:

- Subjects are ready without wearing shoes and sit back with shoes put $23 \mathrm{~cm}$ at the back to perform the test.

- Subjects are required to press the start switch. Wait for a bit sound.

- Put the body in a state of $90^{\circ}$. Then, wait for 2 bit sound and the reading will be taken.

- Next, a bit sound will blowand the subject started to push the gauge to get the first reading of maximum range.

- After 3 seconds, the reading of the actual maximum range will be displayed on the computerized device.

- Press the reset switch to repeat the test.

\subsection{Back Saver Sit and Reach}

Purpose: To measure the flexibility of hamstring muscle on both legs.

Level: Aged between 10 to 17 years.

Gender: Male and female. 
Tools: Gauge range equipment, wooden long ruler (measuring).

\subsection{Electromyography Test}

Electromyography Test is a test to examine the functionality of muscles involved in performing DSR. It uses blue tooth signals (sensor) that attaches to the examined muscles to study the muscle'sopenness and contraction involved. This sensor can also be attached to various muscles to obtain data in any other studies. The muscles tested are biceps brachii, triceps brachii, rectus abdominal, trapezius lower, biceps femoris and biceps femoris. The researchers conducted the tests with a laboratory assistant in the laboratory of UniversitiPendidikan Sultan Idris, TanjungMalim, Perak. Data was generated by electromyography software in computer.

\section{RESULTS AND DISCUSSION}

\subsection{Is there a significant correlation of scores between DSR and BSR on primary school students aged 10?}

Table 1. Result of relation between DSR and BSR

\begin{tabular}{cccc}
\hline Test & & DSR & BSR \\
\hline DSR & Pearson Correlation & 1 & $0.930^{* *}$ \\
& Sig. (2-tailed) & & 0.000 \\
& N & 60 & 60 \\
BSR & Pearson Correlation & $0.930^{* *}$ & 1 \\
& Sig. (2-tailed) & 0.000 & \\
& N & 60 & 60 \\
$* *$ Correlation is significant at 0.01 (two-tailed).
\end{tabular}

Based on Table 1, the results show that there is a strong and significant relationship between DSR with BSR aged $10(\mathrm{r}=0.93, \mathrm{p}=0.001, \mathrm{p}<0.001)$. A test that can achieve a correlation coefficient of 0.85 to 0.93 reliability, with validity exceeding 0.85 to 0.93 is acceptable in measuring [12]. Statistical analysis has shown the correlation between test scores of DSR and BSR is $0.93(\mathrm{~N}=60, \mathrm{p}<0.001)$. A significant relationship between two tests can be identified by the Pearson product moment correlation method to obtain the positive correlation value between the two variables [18-20]. 


\subsection{Is there a significant relationship between the scores of pre-test and post-test in the DSR of primary school students aged 10?}

Table 2. Relation between pre-test and post-test using DSR

\begin{tabular}{cccc}
\hline Test & & Pretest & Posttest \\
\hline Pretest & Pearson Correlation & 1 & $0.97^{* *}$ \\
& Sig. (2-tailed) & & 0.000 \\
N & 60 & 60 \\
P & 30.2333 & \\
& SD & 6.01796 & \\
& Sig. (2-tailed) & 0.000 & \\
& N & 60 & 60 \\
& M & & 31.0500 \\
$* *$ Correlation is significant at 0.01 (two-tailed).
\end{tabular}

Table 2 shows the results with the value of the correlation coefficient $r=0.97$. This fact has been reported that the validity and reliability of the correlation coefficient of 0.80 and above define that the test can give consistent results when tested repeatedly [16].The higher the value and the level of validity and reliability of the instrument, the more accurate the data will be collected to produce good-quality studies [20]. The results of the study is to identify the relationships between pretest and posttest in DSR.

3.3. What are the muscles involved in DSR for primary school students aged 10 ?

Table 3. Results of electromyography test

\begin{tabular}{cc}
\hline Muscles Involved & \% of MVC \\
\hline Biceps Femoris & 85.26 \\
Trapezius Lower & 22.18 \\
Rectus Abdominal & 20.23 \\
Rectus Femoris & 17.16 \\
Triceps Brachii & 14.52 \\
Biceps Brachii & 12.68 \\
\hline
\end{tabular}


Based on Table 3, percentage of Maximum Voluntary Contraction (MVC) analysis on muscle activities while performing DSR with electromyographic test in laboratory studies. Biceps femoris $(85.26 \%)$, trapezius lower $(22.18 \%)$ and rectus abdominal $(20.23 \%)$ showed that muscles highly respond to the test performance. Meanwhile, the lower functioning muscles during the performance of DSR are rectus femoris (17.16\%), triceps brachii $(14.52 \%)$ and biceps brachii (12.68\%). These findings indicate that DSR are significant impact on biceps femoris and inline with previous study that show the biceps femoris as the most muscle active during DSR test [21-22].

\section{CONCLUSION}

The results from the study carried out shows that DSR and BSR have a strong correlation in measuring the flexibility of primary school students aged 10 in SK Jalan Hang Tuah 2, Kuala Lumpur. Therefore, the DSR is a new innovation alternative instrument that can be used to administer the NPFStests on students of SekolahKebangsaanJalan Hang Tuah 2, Kuala Lumpur and also for the country. This DSR involves 10 years-old primary school students only. The researchers suggest that DSR involves students from different age such as 11 years and 12 years. The using more samples will strengthen the findings obtained. In addition, the researchers propose that the future researchers can study the relationship between DSR and other flexibility tests. This study conducted by researchers is based on BSR only by linking other flexibility tests, the future researchers can reinforce the correlation validity to the findings from this test.

\section{REFERENCES}

[1] Blair S T, Kohl H W, Paffenbarger R S, Clark D G, Cooper K H, Gibbons L W.Physical fitness and all-cause mortality: a prospective study of healthy men and women. Journal of American Medical Association, 1989, 262(17):2395-2401

[2] Paffenbarger R S, Blair S N, Lee I M.A history of physical activity, cardiovascular health and longevity: the scientific contributions of Jeremy $\mathrm{N}$ Morris, DSc, DPH, FRCP. International Journal of Epidemiology, 2011, 30(50):1184-1192

[3] Young D R, Steinhard M A.The importance of physical fitness versus physical activity for 
coronary artery disease risk factors: A cross-sectional analysis.Research Quarterly for Exercise and Sport, 1993, 64(4):377-384

[4] Berlin A J, Colditz A G. A meta-analysis of physical activity in the prevention of coronory heart disease. American Journal of Epidemiology, 1990, 132(4):612-628

[5] Bijnen F C H, Caspersen C J, Mosterd W L. Physical inactivity as risk factor for coronary heart disease. A WHO and International Society and Federation of Cardiology Position Statement, 1994, 72(1):1-4

[6] Katzmaryk P T, Malina R M, Thomas M, Song K, Bouchard C. Physical activity and health-related fitness in youth: A multivariate analysis. Medicine Science in Sport and Exercise, 1998, 30(5):709-714

[7] Paffenbarger R S, Kampert J B, Hyde R T, Leung R W, Lee I M, Wing A L. Changes in physical activity and other lifeway patterns influencing longervity. Medicine and Science in Sports and Exercise, 1993, 26(7):857-865

[8] Kasmini K, Idris M N, Fatimah A, Hanafiah S, Iran H, Asmah B M. Prevalence of overweight and obese school children aged between 7-16 years amongst the 3 major ethnic groups in Kuala Lumpur, Malaysia. Asia Pacific Journal of Clinical Nutrition, 1997, 6(3):172-174

[9] Dan S P, Mohd N M T, Zalilah M S. Determination of factors associated with physical activity levels among adolescents attending school in Kuantan. Malaysian Journal of Nutrition, 2011, 17(2):175-187

[10] Rengasamy S, Raju S, Wee A S S L, Rao R. A fitness intervention program within a physical education class on cardiovascular endurance among Malaysia secondary school students. Malaysian Online Journal of Education and Science, 2013, 2(1):1-8

[11] Johnson B. L., Nelson J. K. Practical measurement for evalution in physical education. New York: Macmillan Publishing Company, 1986

[12] Baumgartner T. A., Jackson A. S. Measurement for evaluation in physical education and exercise science. New York: McGraw-Hill, 1998

[13] Sharifah N. A. Amalandalampendidikanjasmanidi Malaysia. Selangor: Pearson, 2012

[14] Ceylan H I, Saygin O,Irez G B. The examining body composition, sprint and coordination characteristics of the children aged 7-12 years. The Anthropologist: International Journal of Contemporary and Applied Studies of Man, 2014, 18(3):859-867 
[15] Cooper Institute for Aerobics Research. The prudential FITNESSGRAM test administration manual. Texas: Cooper Institute for Aerobics Research, 1994

[16] Ahmad H. Pengukurankecergasan motor. Perak: Quantum Books, 2003

[17] Rossett A. Training needs assessment. New Jersey: Educational Technology Publications, 1987

[18] Mohd I S, Norkhalid S, Gunathevan E.The Validity and Reliability of ISO Test towards the Performance Assessment of Future Physical Education Teachers in Teaching and Learning Process. Procedia-Social and Behavioral Sciences, 2015, 195(12):814-820

[19] Norkhalid S, Julismah J, Mohd I S, Gunathevan E.Validity and reliability of comprehensive assessments for handball and badminton games in physical education. Asian Social Science, 2015, 11(23):12-21

[20] Ahmad H. Panduananalisis data secaraefisien: Panduanlengkapberajahuntukmenganalisis data. Selangor: Dubook Press Sdn. Bhd, 2014

[21] Ayala F, Sainz D B, De S C, Santonja F. Reproducibility and criterion related validity of the sit and reach test and toe touch test for estimating hamstring flexibility in recreationally active young adults.Physical Therapy inSport, 2012, 13(4):219-226

[22] Mayorga V D, Merino M R, Viciana J.Criterion related validity of sit and reach tests for estimating hamstring and lumbar extensibility: A meta-analysis.Journal of Sports Science and Medicine, 2014, 13(1):1-14

\section{How to cite this article:}

N.Salimin, M. N. F. Mohammad Zainuri,M. I.Shahril, R. Jaafarand M.Sankaravel. Relation between protocol testdigital sit and reach with back saver sit and reach among 10 years old in primary school. Fundam. Appl. Sci., 2017, 9(5S), 49-57. 